\title{
Some Legal Aspects of the Circulation and Research of Narcotic Drugs and Precursors
}

\author{
Kofanov Andrii \\ Legal Advisor to the Council of Europe Programme "Decentralization and \\ Territorial Consolidation in Ukraine”, PhD of Juridical Sciences, Associate \\ Professor, Professor of Department of Forensic Support and Forensic \\ Expertise of the National Academy of Internal Affairs, Kiev, Ukraine \\ ORCID ID 0000-0002-5242-2518 kofanov_andrey@ukr.net
}

\section{Pavlovska Nataliia}

PhD of Juridical Sciences, Associate Professor, Professor of Department of Civil Law and Process of the National Academy of Internal Affairs, Kiev,

Ukraine ORCID ID 0000-0003-3311-0364 wwwpav@gmail.com

\section{Svoboda Eugenia}

PhD of Juridical Sciences, Associate Professor, Professor of Department of Forensic Support and Forensic Expertise of the National Academy of Internal

Affairs, Kiev, Ukraine

ORCID ID 0000-0002-8639-8333 jeechka@ukr.net

\section{Symchuk Anatolii}

Senior Teacher of Forensic Support and Forensic Expertise of the National Academy of Internal Affairs, Kiev, Ukraine ORCID ID 0000-0002-8663-8210 symchukas@gmail.com

\section{Yakovchuk Serhii}

Associate Professor of Fire Training of the National Academy of Internal

Affairs, Kiev, Ukraine

ORCID ID 0000-0001-7066-3860 Yakovchuk_sergiy@ukr.net

\footnotetext{
Abstract

An analysis of criminal law practice suggests that when considering criminal proceedings of various categories (homicide, rape, theft, production, acquisition, storage, transportation and sale of drugs, etc.),
} 
material evidence is often represented by narcotic drugs of both illicit manufacturing and those produced by the pharmaceutical industry.

Narcotic drugs are a group of pharmacologically active substances of plant and synthetic origin that can selectively affect the central nervous system, resulting in the complete loss of consciousness, loss of all types of sensation and relaxation of skeletal muscles (anaesthesia), or a special psychological and physiological state of the human organism, at which the absence of the habitual poison (drug) causes a number of disagreeable sensations requiring periodic drug use [1].

This reaction is explained by the fact that drugs are quickly included in the metabolism and become indispensable to life. Meanwhile, they are not called poison for anything, since they lead to the physical weakening of the organism, and then to inevitable death. Drug use causes the development of drug addiction (from the Greek narke - sleep, numbness and mania - passion, mania) is clearly recognized morbid impulse and addiction to drugs that produce pleasant sedation or agitation (and some drugs - also illusions and hallucinations) followed by the central nervous system depression.

Keywords: narcotic drugs, cannabinoids, quinine, atropine, cocaine, opium alkaloids, strychnine, caffeine, theobromine, platyphyllin, scopolamine, ephedrin, homicide, rape, theft, production, acquisition, storage, transportation and sale of drugs.

\section{Introduction}

So, drugs provoke drug abuse both of a psychological nature (in their absence, the drug addict feels emotional discomfort) and of a physical one (in the absence of drugs, pain occurs due to dysfunctions of some systems till death). The activities of the human being with drug abuse are maintained at a certain level only on condition of the constant narcotic drug usage; therefore, the drug "seeking" gradually turns into the major goal of the drug addict. Inevitably faced with financial problems, drug addicts commit serious crimes in order to defraud funds for the purchase of drugs [2].

Narcotic effect commonly found in many substances, including such widespread ones as nicotine and alcohols (ethyl alcohol). The most pharmacologically active of these substances are classified by the Single Convention on Narcotic Drugs (UN, 1961) as narcotic substances. Amendments to the Single Convention, introduced in accordance with the 1972 Protocol, the 1971 Convention on Psychotropic Substances, the UN Convention against Illicit Traffic in Narcotic Drugs and Psychotropic Substances (1988) were ratified by Ukraine. The list of narcotic drugs, psychotropic substances and precursors subject to special control in accordance with the legislation of Ukraine is approved by the Cabinet of Ministers initiated by the Narcotics Control Committee. There are certain differences in similar lists of different countries pertaining to the certain national peculiarities.

In 1995, the Verkhovna Rada of Ukraine adopted the Law "On the Circulation of Narcotic Drugs, Psychotropic Substances, Their Analogues and Precursors". In 1997, the Department on Combating Illicit Drug Trafficking (UBNON) was established in Ukraine. 
The National Coordination Council for Combating Drug Addiction under the Cabinet of Ministries of Ukraine was in operation [3].

Drug abuse, despite the active development of international cooperation in the combating against drug addiction, assumes literally catastrophic dimensions almost across the globe [4].

\section{Subject and tasks of the forensic examination of narcotic drugs}

The subject of the forensic examination of narcotic drugs is the determination using special knowledge of the facts and circumstances of the criminal event, for which the following tasks are solved: identification of narcotic drug traces on various objects-carriers, except for the human and animal body tissues and organs, as well as waste products of the living organisms, which are the objects of forensic (toxicological) examination; classification of substances as narcotic, indicating their name; establishing the common group belonging of the homogeneous narcotic drugs according to the raw material characteristics, the technology of their processing, storage conditions, etc.; establishing the common source of narcotic drug origin according to their manufacturing place and method; identification of specific masses of narcotic drugs in their individual parts; determination of the method, technology and characteristics of the narcotic drug manufacturing. To classify narcotic plants as a certain class or species, a forensic biological examination is provided. The compliance of the composition, quality of a pharmaceutical product having narcotic or psychotropic action with the requirements of the standards should be established by qualified pharmacists within the framework of a forensic medical examination [5].

The solution of such questions may be put before the forensic expertise of narcotic drugs: 1. Is the substance submitted for examination narcotic? 2. What type of narcotic drugs does the object of examination belong to? 3. Are there any adherings (traces) of narcotic drugs to the objects, the suspect's clothes provided for examination? 4. Are there traces of narcotic substances in the saliva, adherings to the suspect's hands and face? 5. Do the objects under examination have a common source of origin? 6. Did the narcotic drug provided for examination previously belong to this (specific) mass? 7. How is this narcotic drug manufactured?

\section{Objects of forensic examination}


It is advisable to group the objects of forensic examination of narcotic drugs in the following manner: clandestine produced narcotic drugs, extracted from the opium poppy, hemp, as well as from other narcotic plants; illicit synthetic and semisynthetic substances that do not belong to pharmaceutical products, and therefore, their use is prohibited; pharmaceutical products classified as narcotic, including hypnotics and psychotropic substances; whole narcotic plants and their parts; substances camouflaged as narcotic drugs; object-carriers with traces of narcotic drugs, including tools for their clandestine production; precursors.

It should be remembered that mixtures of various narcotic drugs or narcotic drugs with non-narcotic substances may also be provided for examination.

It is advisable to characterize the objects of forensic examination of narcotic drugs that are most widespread in Ukraine [6].

These are, first of all, clandestine produced narcotic drugs obtained from the hemp and opium poppy.

Hemp (cannabis) is a herbaceous, annual, wind-pollinated plant of the mulberry family. Male plants (fimble) have a thin stem compared to more branched female plants (pistillate hemps). In the narcotic drug manufacturing, the upper (apical) leaves and inflorescences (the apical inflorescences) are typically used, which have the greatest amount of active narcotic substances; however, narcotic drugs can also be obtained from leaves, chaff and other wastes from threshing or mechanical harvesting of hemp. Cannabis narcotic drugs are the most widely used drugs in the world.

Cannabinoids are biologically active components of hemp, as well as of narcotic drugs made from them, and are organic matters, a group of terpenic compounds (with their content up to $10 \%$ or more, depending on the type of narcotic drug): Cannabinol (CBN); Cannabidiol (CBD); Tetrahydrocannabinol (THC) and some of their acid derivatives.

The main component responsible for the psychoactive properties of the cannabis plant is THC, a psychotropic substance and a powerful hallucinogen. The content of cannabinoids in hemp depends on their variety, growing region, harvesting terms and methods, and storage conditions.

Clandestine produced cannabis narcotic drugs: Cannabis (marijuana) is any part of the plant with various degree of particle fineness: tops, inflorescences, leaves or their mixture 
with stems (excluding dead-ripe seeds). It has a spicy odour. It can also be used as a raw material for the production of other drugs from hemp. The colour is from light green/green to brown/deep brown; Cannabis resin (slang - hashish) is obtained, as a rule, from the cannabis plant tops by special grinding, sieving and pressing. Hashish can be found both in resinous and in the powdered or compressed state - in the form of lumps, balls, briquettes, slabs of bright green to deep brown colour with a characteristic spicy odour. The microscopic features of the plant are preserved. On the surface of compressed objects, there are imprints of fabric, traces of moulds; Extracts (tinctures) of cannabis or hashish oil, liquid cannabis, liquid hashish is obtained by extraction of cannabinoids using various solvents (gasoline, hexane, alcohol, etc.) or fats (milk), followed by the solvent removal (evaporation). It is oily from brown to almost black liquid of various consistencies with the characteristic odour of solvent. Sometimes tobacco products are impregnated with it, and then the tobacco particles stick together, and their colour becomes dark brown, and coloured spots appear on the paper wrapper.

The same group of clandestine produced narcotic drugs of plant origin include drugs produced from the opium poppy.

The opium poppy is a type of poppy, among which oily and opium forms are distinguished. Despite certain differences, both forms, more or less, contain narcotic substances. The alkaloids of the opium poppy - opium alkaloids - have narcotic properties. It should be noted that alkaloids are nitrogenous physiologically active organic compounds of predominantly plant origin: quinine, atropine, cocaine, opium alkaloids, strychnine, caffeine, theobromine, platyphyllin, scopolamine, ephedrin, etc.

The following drugs are made from the opium poppy using the clandestine production: Opium (slang - ope) is latex, which leaks out from the incisions of the immature poppy seedpods, and then dries out (in the air, the sun, etc.). It occurs as a dark resinous mass, powder, lumps, balls, tiles, cakes or tinctures that bitter to the taste. About $25 \%$ of opium is made up of so-called opium alkaloids (they have more than 25 names). The main ones are morphine (about 10\% of opium), codeine, thebaine, as well as narcotine, papaverine, narceine, which exist as salts of meconic, sulfuric, and lactic acids. In addition to alkaloids, opium also contains proteins, resins, rubber, carbohydrates, fatty acids, mineral salts, and other substances; Raw opium (slang - beast heroin) is latex, which leaks out from 
the incisions of the immature poppy seedpods, and then clots, without additional drying or processing. It has grey-brown colour and peculiar unpleasant odour; Poppy straw, which includes all parts of the mowed opium poppy (dried or not dried), except for seeds. It comes for examination as components of the opium poppy plant, including whole or ground pods, sometimes in a compressed form. Their grinding degree is different; Concentrate of poppy straw (extraction opium, poppy straw extract) is obtained by extracting opium alkaloids using boiling water or organic solvents (alcohol, acetone, and toluene) and evaporating the extracts to resinous condition. It has deep brown colour and dried fruit odour; Acetylated opium is obtained by acetylation of the opium or poppy straw concentrate. It contains acetylated derivatives of morphine, codeine or their mixture.

In Ukraine, a peculiarity of the acetylated opium clandestine production technology is the use of small amounts of acetic anhydride, as a result of which the acetylation reaction sometimes does not reach the end; therefore, in addition to diacetylmorphine (heroin itself), the drug contains morphine, monoacetylmorphine, and acetylcodeine. In recent years, acetylated opium is called heroin in Ukraine. The most common illicit synthetic and semisynthetic narcotic drugs that do not belong to pharmaceuticals, and, therefore, prohibited to use, are as follows: Heroin (diacetylmorphine) is a synthetic derivative of morphine, of white colour, in the form of amorphous or crystalline powders or granules. In most cases, it is not a chemically pure substance, but a multicomponent mixture with monoacetylmorphine, acetylcodeine, morphine, of beige, brown or black colour. Lactose, glucose, quinine, corn starch, barbiturates, novocaine, and caffeine are often added to heroin. It is packed in the cellophane film ("balls") or aluminium foil to protect against moisture; LSD (lysergic acid diethylamide) is made from lysergic acid, a substance isolated from ergot (a fungus that infects cereals and most often parasitizes on the rye spikes). LSD is a psychotropic substance, a hallucinogen. It occurs as a colourless and tasteless liquid or offwhite powder, tablets, or capsules. The liquid is applied to prepunched paper("stamps"), dripped onto sugar; Cocaine (slang - snow) is a white light crystalline powder, odourless, like snow. The poorly purified (grey), the compressed form also occurs; "Crack” (cocaine base) is a super drug derived from cocaine. The "crack" sound is produced when crystals are heated. Pieces of brown, yellow, pink or white colour, small, hard, semi-translucent, similar to laundry soap, grind and smoke with glass pipes, mix with marijuana or tobacco; 
"Speedball" is a mixture of "crack" and heroin; Ephedrone (slang - tweeker) is colourless, light-yellow, yellow, brown, sometimes red liquid, which is obtained from ephedrine or pseudoephedrine - an alkaloid of the Mongolian ephedra shrub or a synthetic analogue. It has a bitter almond odour; MDMA (3,4-methylenedioxymethamphetamine, slang - ecstasy, wheels) from white to light brown powder, tablets or capsules of different colours. The tablets contain an embossed pattern (bunnies, elephants, camels, etc.). Sometimes drinks are made from it.

The third group consists of pharmaceutical products classified as narcotic.

These are, first of all, opiates - pharmaceuticals obtained from opium, containing the main opium alkaloids and their synthetic substitutes: Omnopon is opium, partially purified from ballast substances. It contains $50 \%$ of morphine and up to $35 \%$ of other alkaloids. It is used as a cream to brown-yellow powders or colourless or brown-yellow solutions; Morphinum (slang - morph). Such pharmaceutical products as morphine hydrochloride, ethylmorphine hydrochloride and others are manufactured in the form of capsules, tablets, white powders, and solutions - in ampoules or syringe-tubes. The technical morphine is not a dosage form. It is made by clandestine production; Codeine is a pharmaceutical represented by a white powder "codeine phosphate"; Promedol is a synthetic medicine of morphine-like action in the form of white tablets (powder), colourless solutions in ampoules or syringe-tubes ( $1 \mathrm{ml}$ each); Methadone is chemically different from morphine but similar in action. For several decades, it has been widely used in the foreign treatment programmes for detoxification of the patients with heroinomania. It is an oral drug substitute. The analogues of the aforementioned and other opiates are sometimes illicitly manufactured in the clandestine laboratories [7].

In recent years, psychotropic and hypnotic drugs of narcotic action from the List $B$ of superpotent substances have been illegally used, which are as follows: Hypnotics of narcotic action are primarily barbituric acid derivatives - barbiturates; although there are more than 2500 barbiturates (in the form of tablets, powders, and solutions), in Ukraine, barbital, sodium pentobarbital (nembutal), cyclobarbital, phenobarbital, benzonal, and hexamylene are most often found in illicit trafficking. Drug addicts also use hexenal, noxyron, sombrevin, which are used in medical practice for the non-inhalation anaesthesia; Psychotropic agents, which make up a group of medications with a specific action on the 
psychic state. Unlike narcotic drugs, they are able to regulate the altered psychic state, and not just influence on it; therefore, they are used to treat psychiatric illnesses. Sedative (psycholeptic) drugs include aminazin, and stimulating agents (psychoactivators) - so-called amphetamines: phenamine, pervitin, phenatin, etc., as well as clophelin. The pharmaceutical product "amphetamine sulfate" is represented as white powders or tablets. The clandestine produced amphetamines are white, pink, yellow, brown, often wet powders or tablets, which have an unpleasant (characteristic) odour due to the residues of organic impurities.

The narcotic plants, which make up the next classification category, include, first of all, various species of hemp and opium poppy [8]. Interestingly, the cultivation of opium poppy plants for seed production is allowed only if the morphine content in the dried straw is not more than $0.15 \%$, and hemp plants - provided that the THC content in the dried straw is not more than $0.15 \%$.

In the countries of Central Asia and in the Crimea, Mongolian ephedra containing the precursor ephedrine grows. Among the exotic plants, it should be noted the coca bushes (coca), cola trees, as well as betel shrubs, mate trees, some types of cacti, mushrooms, etc. It should also not be overlooked that alkaloids are found in tea leaves (caffeine, theobromine, etc.), tobacco (nicotine), and coffee beans (caffeine). Although alkaloids are found mainly in leaves, sometimes in seeds, fruits, roots; therefore, various parts of the plant are used for the clandestine production of drugs.

Substances camouflaged as narcotic include those used to "dilute" drugs or to falsify them. These are, first of all, tobacco, dry nettle, dry fishfood, spongilla, basma, henna, balsam, mummijo, "naswar", and others.

Precursors are substances and their salts classified in international conventions as chemicals used for the manufacture of narcotic drugs and psychotropic substances, as well as chemicals and their salts used for the same purpose and classified in this category by the Drugs Control Committee [9].

The most common precursors should be considered potassium permanganate, crystalline iodine, "red phosphorus", acetic anhydride $(\mathrm{pH}=7)$, inorganic acids (sulfuric, hydrochloric) and organic solvents (acetone, toluene, diethyl ether), various medications (sunoreph, broncholytin, theophedrin, solutan containing ephedrin), and others [10]. 
Conclusions So, the most common object-carriers with traces of drugs are as follows: clothing and human body (especially hands and face); drug taking instruments: syringe, needle, tourniquet, paper tubes for inhaling cocaine, spoons, and empty packages of drugs; tools for clandestine production designed for processing plants and making extracts (coffee grinders, grinding machines, mortars, sieves, moulds, pots, knives, scrapers, fabrics, bandages, cotton pads, especially if they have a characteristic green or brown "grassy" powdery coating), as well as laboratory ware for the distillation, purification and synthesis of drugs.

\section{References}

1. Criminal investigations of narcotic drugs. URL : http://elar.naiau.kiev.ua/jspui/handle/123456789/2990

2. Expertise in judicial practice: scientific and practical textbook. / Under general edit. by V. H. Honcharenko. - [2nd ed., revised and enlarged]. - K. : Yurinkom Inter, 2010. $400 \mathrm{p}$.

3. Moiseenko I. Ya. Commissioning of forensic examinations in the investigation of crimes related to narcotic drug trafficking / I. Ya. Moiseenko // Bulletin of Perm University. - 2010. - No. 2 (8). - P. 198-206.

4. Dovhan A. A. From the experience of the Netherlands Forensic Institute / A. A. Dovhan // Expert and forensic support for the detection and investigation of crimes: practice, experience, problems / Under general edit. by I.P. Krasiuk. - K. : State Research Expert \& Forensic Centre of the MIA of Ukraine, 2010. - Issue 17. - P. 25-30.

5. Koldin V. Ya. Investigative and expert situation as a basis of information interaction between a criminal investigator, an expert and a specialist in the investigative proceedings / V. Ya. Koldin // Forensic examination. Scientific and practical journal. Saratov : Publishing house of the Saratov Law Institute of the MIA of the RF, 2005. - No. 2. - P. 12-18.

6. Law of Ukraine "On Counter the Illicit Trafficking of Narcotic Drugs, Psychotropic Substances and Precursors and Their Abuse", No. 62/95-VR, dated 15.02.1995. - Electronic resource. - Access mode: http://zakon3.rada.gov.ua/laws/show/62/95\%D0\%B2\%D1\%80.

7. Puptseva A. V. Peculiarities of the expert examination performance at the initial stage of the investigation on crimes related to the illicit traffic in narcotic drugs and psychotropic substances / A. V. Puptseva // Gaps in Russian legislation. - 2009. - No. 1. - P. 236-237.

8. Klevtsov V. V. The use of special knowledge in the investigation of crimes related to the illicit traffic in narcotic drugs and psychotropic substances: monograph / V. V. Klevtsov, S. A. Tishkov. - Orel : OrLU of the MIA of the RF, 2012. - 158 p. 
9. Kogosov A.P. Forms of using special knowledge in the investigation of crimes related to the illicit traffic in narcotic drugs or their analogues: [monograph] / A. P. Kogosov, A. V. Petrov. - M. : Yurlitinform, 2012. - 200 p.

10. Strigun D. Yu. Technical and forensic provision for the detection and investigation of the illicit drug trafficking: thesis for a Cand. Degree in Law Sc. in the spec. : 12.00.09 - criminal procedure and forensic science; forensic examination; investigative activities / D. Yu. Strigun. - K. : NAIA, 2011. - 279 p. 